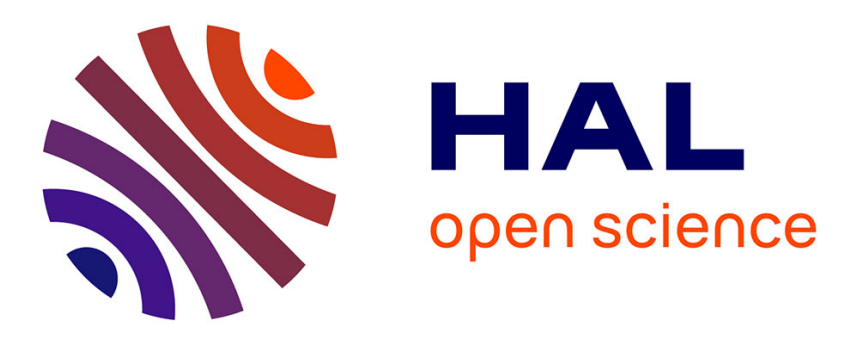

\title{
Modulation of spontaneous and odorant-evoked activity of rat olfactory sensory neurons by two anorectic peptides, insulin and leptin
}

\author{
Agnès Savigner, Patricia Duchamp-Viret, Xavier Grosmaitre, Michel Chaput, \\ Samuel Garcia, Minghong Ma, Brigitte Palouzier-Paulignan
}

\section{To cite this version:}

Agnès Savigner, Patricia Duchamp-Viret, Xavier Grosmaitre, Michel Chaput, Samuel Garcia, et al.. Modulation of spontaneous and odorant-evoked activity of rat olfactory sensory neurons by two anorectic peptides, insulin and leptin. Journal of Neurophysiology, 2009, 101 (6), pp.2898-2906. 10.1152/jn.91169.2008 . hal-02661736

\section{HAL Id: hal-02661736 \\ https: / hal.inrae.fr/hal-02661736}

Submitted on 30 May 2020

HAL is a multi-disciplinary open access archive for the deposit and dissemination of scientific research documents, whether they are published or not. The documents may come from teaching and research institutions in France or abroad, or from public or private research centers.
L'archive ouverte pluridisciplinaire HAL, est destinée au dépôt et à la diffusion de documents scientifiques de niveau recherche, publiés ou non, émanant des établissements d'enseignement et de recherche français ou étrangers, des laboratoires publics ou privés. 


\section{Agnès Savigner, Patricia Duchamp-Viret, Xavier Grosmaitre, Michel Chaput, Samuel Garcia, Minghong Ma and Brigitte Palouzier-Paulignan \\ J Neurophysiol 101:2898-2906, 2009. First published Mar 18, 2009; doi:10.1152/jn.91169.2008}

You might find this additional information useful...

This article cites 52 articles, 20 of which you can access free at:

http://jn.physiology.org/cgi/content/full/101/6/2898\#BIBL

Updated information and services including high-resolution figures, can be found at:

http://jn.physiology.org/cgi/content/full/101/6/2898

Additional material and information about Journal of Neurophysiology can be found at: http://www.the-aps.org/publications/jn

This information is current as of May 11, 2010 . 


\title{
Modulation of Spontaneous and Odorant-Evoked Activity of Rat Olfactory Sensory Neurons by Two Anorectic Peptides, Insulin and Leptin
}

\author{
Agnès Savigner, ${ }^{1,2}$ Patricia Duchamp-Viret, ${ }^{1}$ Xavier Grosmaitre, ${ }^{2}$ Michel Chaput, ${ }^{1}$ Samuel Garcia, ${ }^{1}$ \\ Minghong $\mathrm{Ma}^{2}$ and Brigitte Palouzier-Paulignan ${ }^{1}$ \\ ${ }^{1}$ Université de Lyon, Centre National de la Recherche Scientifique, Unité Mixte de Recherche 5020, Neurosciences Sensorielles, \\ Comportement, Cognition, Lyon, France; and ${ }^{2}$ Department of Neuroscience, University of Pennsylvania, School of Medicine, Philadelphia, \\ Pennsylvania
}

Submitted 22 October 2008; accepted in final form 12 March 2009

\begin{abstract}
Savigner A, Duchamp-Viret P, Grosmaitre X, Chaput M, Garcia S, Ma M, Palouzier-Paulignan B. Modulation of spontaneous and odorant-evoked activity of rat olfactory sensory neurons by two anorectic peptides, insulin and leptin. J Neurophysiol 101: 2898-2906, 2009. First published March 18, 2009; doi:10.1152/jn.91169.2008. In mammals, the sense of smell is modulated by the status of satiety, which is mainly signaled by blood-circulating peptide hormones. However, the underlying mechanisms linking olfaction and food intake are poorly understood. Here we investigated the effects of two anorectic peptides, insulin and leptin, on the functional properties of olfactory sensory neurons (OSNs). Using patch-clamp recordings, we analyzed the spontaneous activity of rat OSNs in an in vitro intact epithelium preparation. Bath perfusion of insulin and leptin significantly increased the spontaneous firing frequency in $91.7 \%(n=24)$ and $75.0 \%(n=24)$ of the cells, respectively. When the activity was electrically evoked, both peptides shortened the latency to the first action potential by $\sim 25 \%$ and decreased the interspike intervals by $\sim 13 \%$. While insulin and leptin enhanced the electrical excitability of OSNs in the absence of odorants, they surprisingly reduced the odorant-induced activity in the olfactory epithelium. Insulin and leptin decreased the peak amplitudes of isoamyl acetate-induced electroolfactogram (EOG) signals to 46 and $38 \%$, respectively. When measured in individual cells by patch-clamp recordings, insulin and leptin decreased odorant-induced transduction currents and receptor potentials. Therefore by increasing the spontaneous activity but reducing the odorant-induced activity of OSNs, an elevated insulin and leptin level (such as after a meal) may result in a decreased global signalto-noise ratio in the olfactory epithelium, which matches the smell ability to the satiety status.
\end{abstract}

\section{IN T R O D U C T I O N}

The sense of smell is critically involved in eating behaviors from food detection to consumption. Addition of certain odorants to a diet has a profound influence on the amount of food rats consume (Le Magnen 1956, 2001), and loss of smell in bulbectomized rats leads to long-term compulsive overeating (hyperphagia) (Seguy and Perret 2005). Conversely, the nutritional status regulates the olfactory function (Chaput and Holley 1976), e.g., fasted rats have better smell abilities than satiated ones (Aimé et al. 2007).

The interplay between food intake and olfaction is mostly mediated by peptide hormones produced in various tissues according to an animal's satiety status. Ghrelin, secreted from

Address for reprint requests and other correspondence: A. Savigner, Dept. of Neuroscience, University of Pennsylvania, School of Medicine, 215 Stemmler Hall, 3450 Hamilton Walk, Philadelphia, PA 19104 (savigner@mail.med. upenn.edu) the stomach, signals hunger, while insulin from the pancreas and leptin from the adipose tissue mainly signal satiety. These peptides, carried by the blood flow, inform the food-intake regulatory centers in the brain including the hypothalamic nuclei, which in turn produce orexigenic (e.g., orexin) or anorexigenic peptides to initiate or to stop food intake (Arora and Anubhuti 2006; Plum et al. 2005; Schwartz et al. 2000; Stanley et al. 2005). In a behavioral study, intracerebroventricular injection of orexin or leptin increases or decreases the olfactory sensitivity, respectively (Julliard et al. 2007). Consistent with this finding, mutant mice lacking leptin or leptin receptors performed significantly better than wild-type animals in an olfactory-mediated, food-finding test (Getchell et al. 2006).

While the food intake peptides can exert their actions on the olfactory system centrally in the brain, e.g., the olfactory bulb (Fadool et al. 2004; Hardy et al. 2005; Palouzier-Paulignan et al. 2006), this study focuses on their effects on the peripheral sensory neurons in the olfactory epithelium. Several peptides (orexin, insulin, and leptin) are present in the olfactory mucosa, and their receptors and signaling machineries are identified in olfactory sensory neurons (OSNs) and other cell types (Baly et al. 2007; Getchell et al. 2006; Gorojankina et al. 2007; Lacroix et al. 2008). Insulin and leptin, two anorectic peptides, are of special interest because their levels as well as their receptor levels in the olfactory epithelium are regulated by the nutritional status (Baly et al. 2007; Getchell et al. 2006; Gorojankina et al. 2007; Lacroix et al. 2008). However, the effects of an elevated level of insulin or leptin (such as after a meal) on the functional properties of single OSNs are unknown.

Here we investigated the effects of insulin and leptin on individual OSNs in the absence or presence of odorants. We first studied the spontaneous activity, which is critical for the survival of OSNs by stabilizing their projections to the olfactory bulb (Yu et al. 2004). We characterized the firing patterns of rat OSNs in the intact epithelium preparation via patchclamp recordings and examined the consequences of bath perfusion of insulin and leptin. Both peptides enhanced the excitability of OSNs by increasing the spontaneous firing frequency and reducing the interspike intervals in electrically evoked spike trains. This is surprising considering the recent report that insulin decreases the odorant responses of the olfactory epithelium in electroolfactogram (EOG) recordings (Lacroix et al. 2008). We then confirmed that insulin (as well as leptin) decreased the EOG signals induced by isoamyl acetate. We further revealed that these two peptides reduced 
the odorant responses at the single-cell level using patch-clamp recordings. The results suggest that these circulating hormones, mostly known to regulate energy homeostasis, may modulate the smell function by altering the spontaneous and odorantinduced activity of OSNs.

\section{METHODS}

The animal-handling procedures followed the European Community Council Directive 86/609/EEC for the care and use of laboratory animals and the guidelines of the Institutional Animal Care and Use Committee of the University of Pennsylvania.

\section{Patch-clamp recordings}

Wistar rats were used at the age of P6-P15 because OSNs from younger preparations survive longer. Animals were deeply anesthetized using $0.02 \mathrm{ml}$ ketamine $(100 \mathrm{mg} / \mathrm{ml})$ and decapitated. The whole head was quickly immersed in cold Ringer solution $\left(2-4^{\circ} \mathrm{C}\right)$. A paramedial sagittal section of the nose allowed harvesting the medial septum that separates the two nasal cavities. Olfactory mucosa were peeled off from both sides of the septum and kept in cold, oxygenated Ringer solution. Under an upright microscope (Olympus BX61WI) equipped with a CCD camera (Dage-MTI) and a fourfold magnification changer, the dendritic knobs of OSNs were visualized through a $\times 40$ water-immersion objective.

After being transferred to the recording chamber, mucosa explants were continuously perfused with oxygenated Ringer $(2.5 \mathrm{ml} / \mathrm{min}$ at $25 \pm 2^{\circ} \mathrm{C}$ ). Recordings were performed on the knobs of OSNs in either cell-attached or perforated patch-clamp configuration. In cellattached configuration, borosilicate pipettes $(1.2 \mathrm{~mm}$ OD, $0.69 \mathrm{~mm}$ ID, Sutter Instruments) were filled with Ringer solution, and the seal resistance was $2-3 \mathrm{G} \Omega$. In perforated patch-clamp configuration, the recording pipettes were filled with the internal solution (see following text), and the seal resistance was 1-2 G $\Omega$. The membrane potential was hyperpolarized $\left(V_{\text {hold }}=-80 \mathrm{mV}\right)$ to prevent exhaustion of the cells from the frequent firing. The junction potential $(10 \mathrm{mV})$ was corrected in all recordings a posteriori. Data were acquired with an EPC9 amplifier combined with the Pulse software (HEKA Electronic). The sampling frequency was $10 \mathrm{kHz}$ in current-clamp and 5 $\mathrm{kHz}$ in voltage-clamp mode. Signals were filtered at a frequency equal to half of the sampling frequency.

Insulin (human recombinant insulin, $0.5 \mu \mathrm{g} / \mathrm{ml}$, i.e., $86 \mathrm{nM}$, Sigma) or leptin (rat recombinant leptin, $50 \mathrm{nM}$, Sigma) was dissolved in Ringer solution and perfused the entire explants. We used the peptide concentrations within the physiological range of adult insulinemia and leptinemia (see DISCussion for references). Insulin at this concentration is efficient in the olfactory bulb without interacting with insulin like growth factor pathways (Fadool et al. 2000). Although the leptin concentration was well below the young rat leptinemia, it appeared to be efficient. Using Ringer solution, we first verified that switching perfusing solutions didn't disrupt the spontaneous firing of OSNs by any mechanical stimulation.

Isoamyl acetate was used to elicit odorant responses because it is an effective ligand for a significant portion of OSNs during in vivo recordings (Duchamp-Viret et al. 2000). Isoamyl acetate was first dissolved in DMSO as a stock solution $(0.5 \mathrm{M})$ and diluted in Ringer solution (final concentration: $100 \mu \mathrm{M}$ ). The odorant stimulation was delivered by pressure ejection via a picospritzer (General Valve) using a pipette placed downstream from the recorded cell. The distance between the puffing electrode and the recording site was adjusted to avoid mechanical stimulation (Grosmaitre et al. 2007). For each cell, the parameters of stimulation were adjusted to elicit reliable middle strength responses (duration of the puff was between 0.1 and $0.5 \mathrm{~s}$ with a $10 \mathrm{psi}$ ejection pressure). The procedure included three stimulations in the control condition, three under drug perfusion (insulin or leptin), and three during washout. The isoamyl acetate stimulations were interspaced by $2 \mathrm{~min}$.

\section{EOG recordings}

Non-weaned P15-P20 or ad-libitum-fed adult Wistar rats were used in either in vivo or in vitro preparations. The in vivo recording procedure has been previously described (Duchamp-Viret et al. 2000). Briefly, animals were anesthetized by intraperitoneal (ip) injection of an initial dose of pentobarbital sodium and chloral hydrate (Equithesine, $3 \mathrm{ml} / \mathrm{kg}$ ) and secured for surgery in a stereotaxic apparatus. Anesthetic was then supplemented to maintain a deep level of anesthesia. Access to the olfactory mucosa was gained by opening a dorsal slit in the nasal bones and the underlying dorsal recess. For in vitro recordings, animals were anesthetized by an injection of pentobarbital sodium (Nembutal $20 \mathrm{mg} / \mathrm{kg}$ ip) and then decapitated. The skin was quickly removed, and the skull was longitudinally cut along the medial suture to expose the nasal cavities. The preparation, surrounded by cottons saturated with Ringer, was fixed into a silicone chamber and was placed under the nozzle of the olfactometer (Vigouroux et al. 1988). For in vivo preparations, the dorsal turbinate was stimulated whereas all turbinates were tested with hemi-head in vitro preparations.

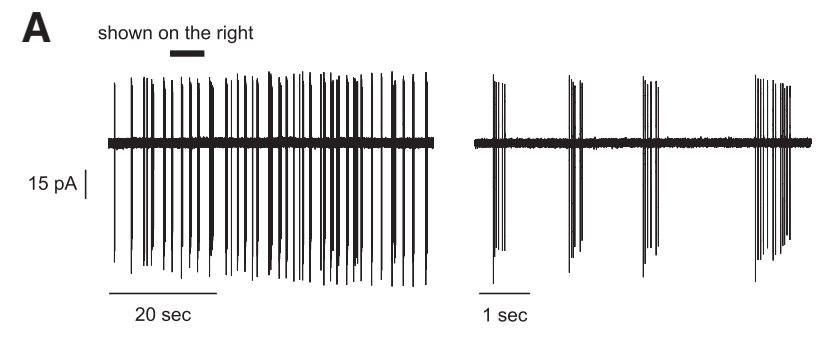

B

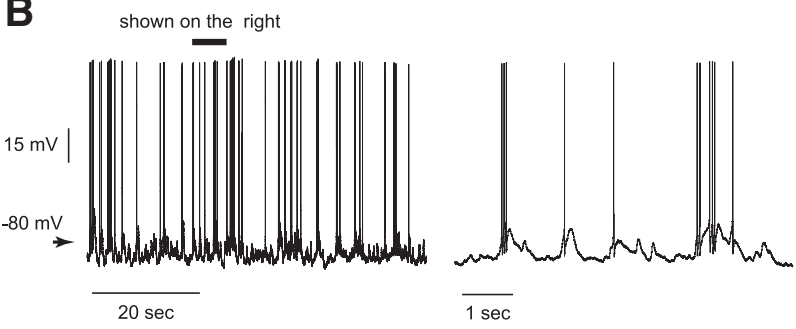

C

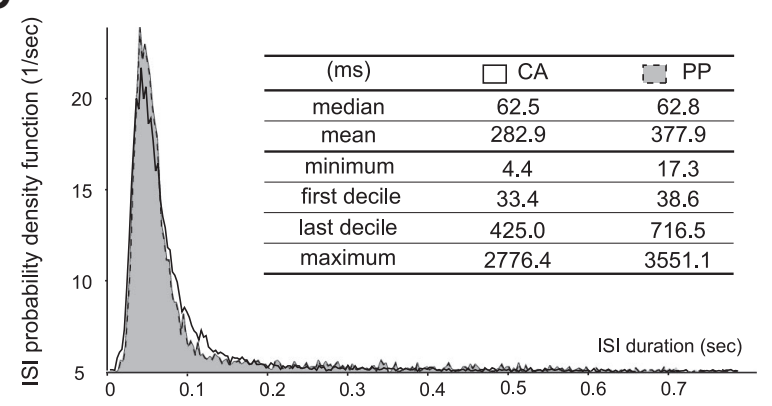

FIG. 1. Rat olfactory sensory neurons (OSNs) show spontaneous bursting activity. $A$ : the spontaneous activity of an OSN was recorded in cell-attached configuration. $\square$, the period enlarged (right) where bursts were evident. $B$ : the spontaneous activity of an OSN was recorded in perforated patch-clamp configuration. Bursts were still present, interspaced by more various interspike intervals (ISIs) than the cell-attached recordings. $\mathbf{n}$, the period enlarged (right) where bursts included fewer action potentials due to the hyperpolarizing current injected into the neuron (see METHODS). $C$ : the probability density functions of ISIs are plotted for both cell-attached (CA) and perforated patch-clamp (PP) recordings. The table summarizes key values describing each distribution (in $\mathrm{ms}$ ). 
Recordings were done using borosilicate glass pipettes $(1.5 \mathrm{~mm}$ OD, $1.17 \mathrm{~mm}$ ID, Clark Electromedical Instruments) filled with Ringer solution. The tip resistance was $2-4 \mathrm{M} \Omega$. The EOG signal was amplified by a conventional amplifier (DC $30 \mathrm{~Hz}$ cutoff) and recorded on a CED-1401 data-acquisition system (Cambridge Electronic Design) connected to a computer for off-line analysis. The odorant stimulations were interspaced by $90 \mathrm{~s}$. Depending on the recording site, the isoamyl acetate concentration was adjusted to a fraction of the saturated vapor (SV) from SV/80 (80 times dilution) to SV/45 (45 times dilution) to obtain 10-15 mV EOG signals.

To apply insulin or leptin, small cubes of gelatin (Agarose VII-A, low gelling temperature, Sigma, $1 \%$ in Ringer) were extemporaneously soaked either with insulin or leptin solutions (86 and $50 \mathrm{nM}$, respectively, in Ringer). A test cube was applied close to the EOG recording site gently enough to avoid disrupting the electrode positioning. On one recording site, using the same isoamyl acetate concentration, five EOG signals were elicited under each of the following conditions: control (with and without a gelatin cube soaked of Ringer), test (with a peptide soaked cube), and recovery (after cube removal). Only runs where the signals remained stable after the application of the Ringer-soaked cubes were included in the analysis.

\section{Recording solutions}

The same Ringer solution was used for both EOG and patch-clamp recordings (in $\mathrm{mM}$ ): $125 \mathrm{NaCl}, 4 \mathrm{KCl}, 25 \mathrm{NaHCO}_{3}, 2 \mathrm{CaCl}_{2}, 1.25$ $\mathrm{NaH}_{2} \mathrm{PO}_{4}, 1 \mathrm{MgCl}_{2}$, and 5.5 glucose. The $\mathrm{pH}$ was kept at 7.6 by oxygenating with $95 \% \mathrm{O}_{2}-5 \% \mathrm{CO}_{2}$, and the osmolarity was adjusted to $320 \mathrm{mOsm}$ with sucrose. Tetrodotoxin (TTX, Sigma) at 1-2 $\mu \mathrm{M}$ was perfused in some of the experiments. As previously described by $\mathrm{Ma}$ and coworkers (2003), for perforated patch-clamp recordings, pipettes were filled with the internal solution containing (in $\mathrm{mM}$ ) 70 $\mathrm{KCl}, 53 \mathrm{KOH}, 30$ methanesulfonic acid, 5 EGTA, 10 HEPES, and 70 sucrose; 310 mosM, pH 7.2 adjusted with KOH. Amphotericin B (stock solution: $3 \mathrm{mg}$ amphotericin $\mathrm{B} / 50 \mu \mathrm{l} \mathrm{DMSO}$ ) was extemporaneously added at a final concentration of $130 \mu \mathrm{M}$.

\section{Data analysis}

The firing properties were analyzed using Open Electrophy (http:// neuralensemble.org/trac/OpenElectrophy), SciPy, and MySql database software (Open Source licenses). The probability density functions of interspike intervals (ISIs) were plotted with an ISI distribution bin of $3 \mathrm{~ms}$ on the $x$ axis, and the total integral of ISI distribution equals $1\left(\int_{\text {ISImin }}^{\text {ISImax }} f(x) d x=1\right)$. Thus the probability for an ISI to fall within the interval $[a<$ ISI $<b]$ is represented as the area under the graph within the interval $[a ; b]$ (i.e., $\left.\int_{a}^{b} f(x) d x\right)$.

Statistics were carried out using R software (R Development Core Team 2007). Nonparametric Wilcoxon signed-rank tests were used to test the mean frequency distribution in the different cell populations recorded under cell-attached or perforated configurations. Nonparametric Wilcoxon matched-paired signed-rank tests were used to compare the firing frequencies, latencies, and ISIs with or without drug application.

\section{RES U L T S}

\section{OSNs fire spontaneously in a bursting mode}

We recorded the spontaneous activity of OSNs in the intact olfactory epithelium under either cell-attached or perforated patch-clamp configuration. The extracellular cell-attached recording permits observation of the cells in a less disturbed condition, whereas the intracellular perforated patch-clamp allows subthreshold events recording and manipulation of the membrane potential by current injection. In either configuration, we could record the cells for as long as $30 \mathrm{~min}$.

Under cell-attached configuration, all neurons $(100 \%, n=$ 27) showed a spontaneous activity with a mean firing frequency of $3.0 \pm 1.7$ (SE) Hz. Most of the OSNs displayed a phasic firing pattern, consisting of bursts of action potentials (Fig. 1A). Under perforated patch clamp, $85.7 \%(n=21)$ of the
A
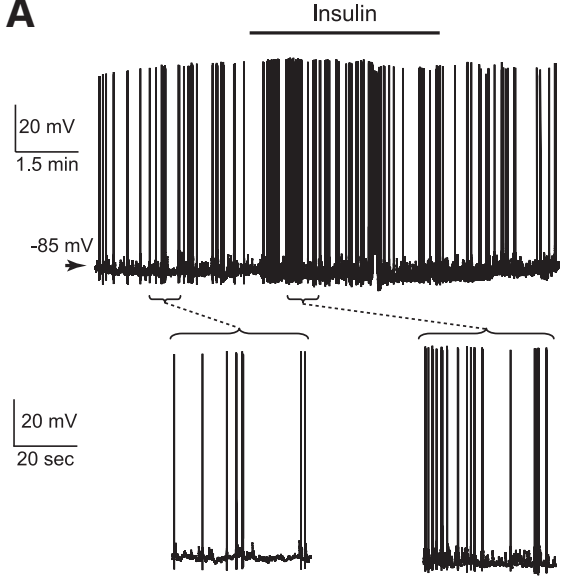

B

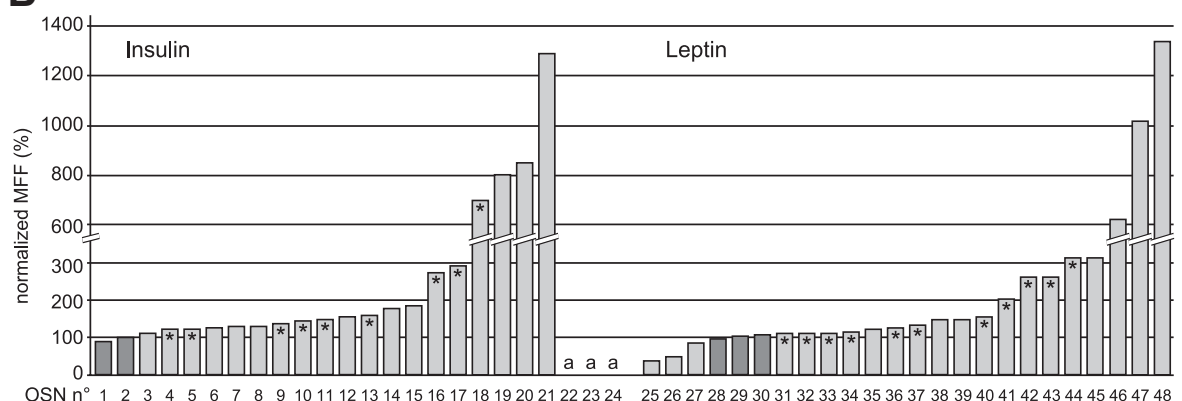

Leptin

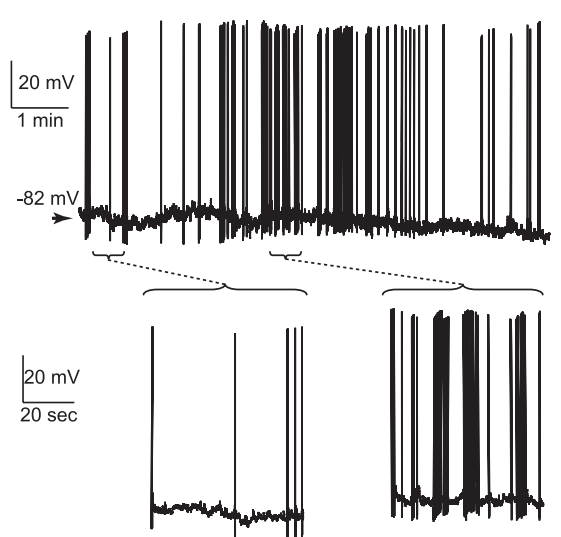

FIG. 2. Insulin and leptin increase the firing frequency of OSNs. $A$ : the spontaneous activity of 2 OSNs was recorded in perforated patch-clamp configuration under current-clamp mode. Within $30 \mathrm{~s}$ of perfusion, insulin increased the mean firing rate of the 1st OSN (left) from 0.3 to $1.0 \mathrm{~Hz}$ and leptin increased the mean firing rate of the 2nd OSN (right) from 0.6 to $1.9 \mathrm{~Hz}$. Both cells recovered during the drug washout (left: to $0.3 \mathrm{~Hz}$ within $30 \mathrm{~s}$; right: to $0.5 \mathrm{~Hz}$ within $2 \mathrm{~min}$ ). The brackets mark the periods enlarged below each recording. $B$ : for each neuron, the mean firing frequency (MFF) recorded during insulin (left) and leptin (right) perfusion was normalized to the control frequency $(100 \%)$. Insulin perfusion had a stimulating effect in 19 neurons (3-21), made the firing appear in 3 silent neurons (22-24, marked as "a"), and did not change the firing frequency in 2 cells ( 1 and 2). Leptin perfusion had a stimulating effect in 18 neurons (7-24), reduced the firing frequency in 3 neurons (1-3), and had no effect on 3 others $(4-6)$. *, a recovery of $\geq 20 \%$ for that cell. Less recovery was observed for the cells showing the most profound modulation by insulin $(19-24)$ or leptin $(45-48)$. 
neurons showed a spontaneous activity with a mean firing frequency of $1.7 \pm 1.3 \mathrm{~Hz}$. Bursts of action potentials were also present but isolated spikes occurred more often (Fig. 1B). The lower firing frequency obtained under this configuration was presumably due to the hyperpolarizing current injected into the cells (see METHODS). Despite the difference in the mean firing frequency, the ISI probability density functions obtained from cell-attached (12,458 ISIs from all recorded cells) or perforated patch clamp (4,712 ISIs) were very similar (Fig. $1 C$ ). Both curves were centered at $41.9 \mathrm{~ms}$ (bin $=3 \mathrm{~ms}$ ) with comparable median values $(62.5 \mathrm{~ms}$ for cell-attached and 62.8 $\mathrm{ms}$ for perforated patch clamp) corresponding to the intraburst firing. These results indicate that OSNs in the intact epithelium fire spontaneously in a bursting mode.

\section{Insulin and leptin enhance the excitability of OSNs}

We next tested the effects of an elevated level of insulin or leptin on the spontaneous activity of OSNs. Bath perfusion of insulin $(86 \mathrm{nM})$ or leptin $(50 \mathrm{nM})$ had a strong stimulatory effect on the OSNs, regardless of their basal spontaneous firing frequency (Fig. 2A). Neurons were considered as sensitive to these peptides when the mean firing frequency changed by $\geq 10 \%$ of the control value. Insulin significantly $(P<0.0001)$ increased the firing frequency in 22 of 24 cells $(91.7 \%)$ within $1 \mathrm{~min}$ and had no effect on the remaining cells (Fig. 2B, left). During the washout period (2-6 min), nine neurons (40.9\%) recovered and the remaining neurons kept firing at a higher frequency. Leptin was tested in another set of 24 neurons. The peptide significantly $(P<0.002)$ increased the mean firing frequency in 18 cells $(75.0 \%)$ within 1 min (Fig. $2 B$, right). Among the remaining neurons, three did not respond to leptin and three showed a decrease in the spontaneous firing. During the washout period (2-6 $\mathrm{min}), 11(61.1 \%)$ of the excited neurons showed a recovery back to the control frequency, and the remaining 7 (38.9\%) kept firing at a higher frequency.

We also tested the effects of insulin and leptin on the evoked activity in rat OSNs. In perforated patch-clamp configuration, during silent periods, a $0.4 \mathrm{nA}$ depolarizing step was repeatedly injected into the neurons under the control condition and during insulin (Fig. $3 A$ ) or leptin perfusion $(B)$. If a spontaneous burst occurred during current injection, the trial was excluded from further analysis. Regardless of the basal excitability level, insulin shortened the latency to the first action potential by $27.5 \%$ (from $66.6 \pm 24.7$ to $48.3 \pm 19.1 \mathrm{~ms}, n=$ $6, P<0.05$ ) and leptin by $24.9 \%$ (from $43.4 \pm 15.6$ to $32.6 \pm$ $12.6 \mathrm{~ms}, n=6, P<0.005$; Fig. $3 C$ ). The ISIs were analyzed to evaluate the effects of both peptides on the firing frequency (Fig. 3D). Both insulin and leptin decreased the mean ISIs by $\sim 13 \%$ : from $49.2 \pm 7.7$ to $42.0 \pm 7.0 \mathrm{~ms}$ by insulin $(n=6$, $P<0.02)$ and from $44.2 \pm 11.9$ to $38.4 \pm 8.3 \mathrm{~ms}$ by leptin $(n=7, P<0.005)$. These data reveal that insulin and leptin increase the neuronal excitability of OSNs.

\section{Odorant stimulation induces various response patterns in OSNS}

We characterized the activity patterns of OSNs induced by isoamyl acetate, an odorant that elicited responses in $74.7 \%$ of the neurons $(n=95)$ with $54.7 \%$ showing excitatory and $20.0 \%$ showing inhibitory responses. Among the excitatory re-
A

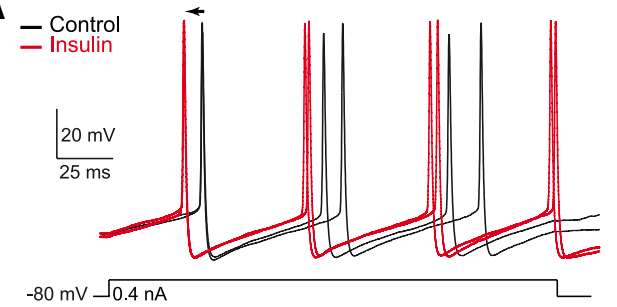

B

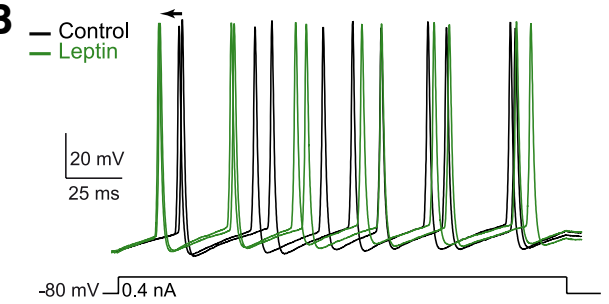

C
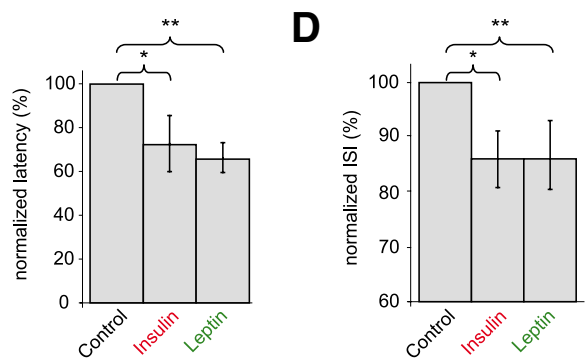

FIG. 3. Insulin and leptin increase the excitability of OSNs in electrically evoked events. $A$ and $B: 2$ neurons were recorded in perforated patch-clamp configuration under current-clamp mode. A depolarizing step of $0.4 \mathrm{nA}$ was repeated in the control condition and during insulin $(A)$ or leptin $(B)$ perfusion. Both hormones shortened the latency to the 1st action potential $(\leftarrow)$ and increased the firing frequency ( 2 traces from each condition are illustrated). $C$ and $D$ : graphs summarize the effects of insulin and leptin on the normalized latency $(C)$ and ISI $(D)$ pooled from 6 cells for each peptide.

sponses, we observed two predominant patterns. First, isoamyl acetate stimulation induced tonic bursts in some neurons, recorded in cell-attached (Fig. 4A, top) or perforated patch-clamp configurations (Fig. 4A, bottom). In the intracellular recordings, the action potentials appeared to be grafted on the depolarizing receptor potential. Second, isoamyl acetate stimulation induced an initial high-frequency burst with decrementing spikes (b), followed by a silence (s), and a rebound (r) period (Fig. 4B). In perforated patch-clamp recordings, the initial burst $(\mathrm{b} ; 52.4 \pm$ $9.2 \mathrm{~Hz}, n=8$ ) was grafted on the rising phase of a long-lasting receptor potential (Fig. 4B, bottom). The sustained depolarization (mean peak amplitude $=38.6 \pm 12.3 \mathrm{mV}, n=13$ ) corresponded to a period (s) during which no action potentials were elicited. The $\mathrm{b} / \mathrm{s} / \mathrm{r}$ pattern was observed in $61.3 \%$ of the OSNs excited by isoamyl acetate versus the simple burst pattern in $38.7 \%(n=31)$. We then measured the inward transduction currents underlying the excitatory responses elicited by isoamyl acetate puffs under voltage-clamp mode. The peak current amplitude ranged between 4 and $478 \mathrm{pA}(n=22$, Fig. $4 C$ ), with $45 \%<25 \mathrm{pA}, 32 \%$ between 25 and $100 \mathrm{pA}$, and $23 \%>100 \mathrm{pA}$. These results demonstrate that rat OSNs display a variety of activity patterns (dominated by the $\mathrm{b} / \mathrm{s} / \mathrm{r}$ pattern) in response to the same odorant.

Notably, addition of 1-2 $\mu \mathrm{M}$ TTX in the bath failed to completely block the spontaneous firing $(n=6$, data not shown) or the odorant-induced spikes (Fig. $4 C, \rightarrow$ ). The TTX 

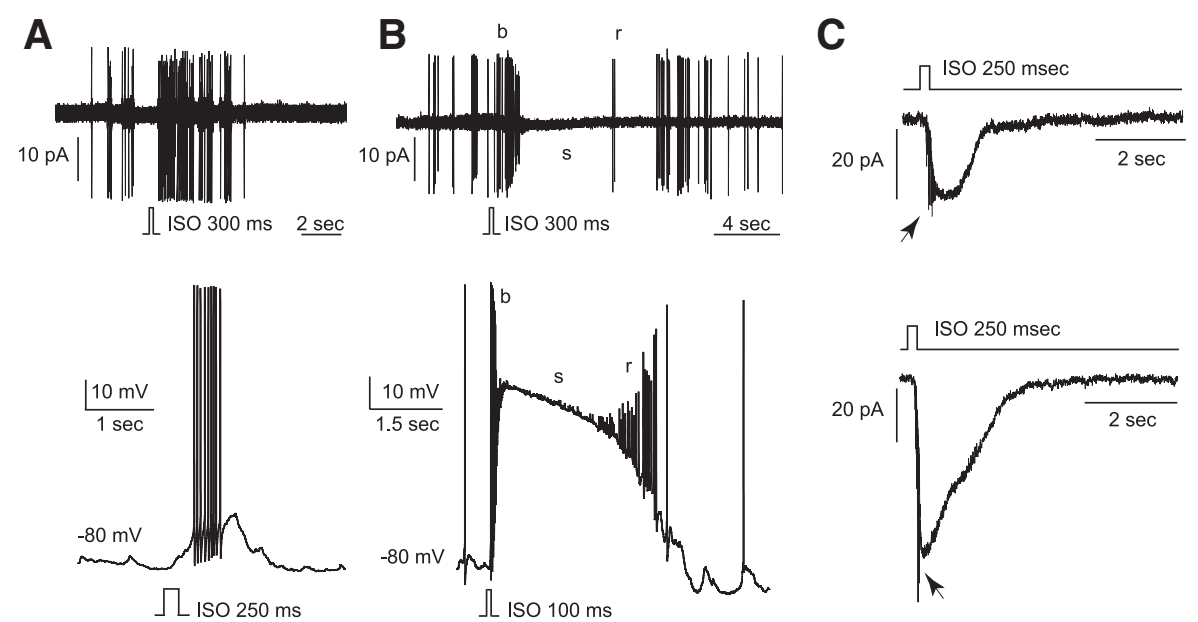

FIG. 4. Odorant stimulation induces various activity patterns in individual OSNs. Two types of responses were frequently observed following stimulation with isoamyl acetate (ISO, $100 \mu \mathrm{M}$, duration is indicated on each picture). A: in some neurons, brief puffs of ISO elicited a nondecrementing burst, observed either in cell-attached (top) or perforated patch-clamp (current-clamp mode) configuration (bottom). B: in other neurons, brief puffs of ISO elicited an initial burst (b) followed by a silence (s) and a firing rebound (r) in cell-attached configuration (top). A similar pattern was observed in perforated patch-clamp configuration (bottom): the initial burst (b) was grafted on a large receptor potential, which kept the membrane potential in a depolarized state (s). During repolarization, the rebound (r) firing appeared before a complete return to the spontaneous activity. $C: 2$ neurons were stimulated for $250 \mathrm{~ms}$ by ISO puffs that elicited a small (top) or a large (bottom) inward transduction current recorded under voltage-clamp mode. Despite the presence of $1 \mu \mathrm{M}$ TTX in the bath perfusion, some action potentials $(\rightarrow$ ) occurred in response to ISO. The holding potential for both cells was $-80 \mathrm{mV}$.

sensitivity of $\mathrm{Na}^{+}$channels in rat OSNs is somewhat controversial in the literature. Acutely dissociated OSNs are highly sensitive (Trombley and Westbrook 1991) in contrast to cultured OSNs (Rajendra et al. 1992). Here we showed that the OSNs in the intact epithelium were not as sensitive as the dissociated neurons.

\section{Insulin and leptin mainly reduce odorant responses of OSNS}

We examined the effects of these two peptides on the odorant-induced activity of OSNs. We initially used EOG recordings to measure the odorant responses from a large population of sensory neurons. The peptide delivery procedure is shown in Fig. 5A, and the high percentage (87\%) of stable control runs verified the undisturbed recording conditions (see METHODS). Results obtained from in vivo and in vitro preparations in young and adult animals were similar and thus pooled together. Insulin decreased the peak amplitude of isoamyl. Acetate-induced EOG signals to $46 \pm 18 \%$ of the control $(n=13, P<0.0002)$, and a recovery to $84 \pm 25 \%$ was observed in 10 recording sessions (Fig. 5B). Leptin decreased the peak amplitude to $38 \pm 19 \%$ of the control $(n=14, P<$ 0.0001 ), and a recovery to $70 \pm 26 \%$ was observed in nine recording sessions (Fig. 5C).

Because the EOG recording does not provide the information at the single-cell level, we next tested the effects of these two peptides on individual OSNs using patch-clamp recordings. Fourteen of 17 neurons (82.4\%) with stable excitatory isoamyl acetate responses showed odorant responses modulated by peptide perfusion. While insulin and leptin increased the spontaneous firing (Fig. 6, $A$ and $B$ ), both peptides mainly reduced the odorant responses by slowing down the initial burst (Fig. 6. $C$ and $D$ ) or decreasing the transduction currents $(66.7 \%, n=12$ for insulin; $60.0 \%, n=5$ for leptin; Fig. $6 E)$, consistent with the decreased EOG signals. However, three neurons ( 2 under insulin and 1 under leptin perfusion) showed an increase of the firing frequency during the initial burst (Fig. 7, A and $B$ ). We suspected that these three cells had such a profound increase in the spontaneous firing frequency, which might have masked the peptide effects on the odorant responses. To test this possibility, we plotted the normalized firing frequencies (to

\section{A}
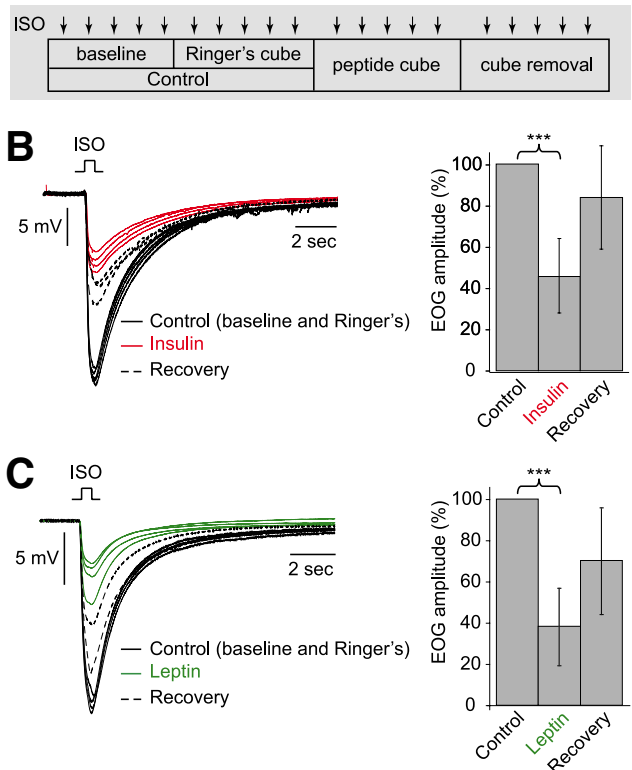

FIG. 5. Insulin and leptin decrease odorant-induced electroolfactogram (EOG) signals. EOG signals were recorded from the surface of olfactory turbinates in response to isoamyl acetate puffs (ISO, SV/80, $0.5 \mathrm{~s}$ ). A: during each experiment, 5 ISO stimulations were delivered in each condition: without any cube, with Ringer-soaked cube, with peptide (insulin or leptin)-soaked cube, and after cube removal. $B$ : in 1 preparation, insulin (red lines, 4 traces being shown) reduced the EOG signals (control recordings in black solid lines, 2 traces from each control condition being shown) with partial recovery (black dotted lines, 3 traces being shown). The graph on the right summarizes the normalized EOG signals from 13 preparations. $C$ : in 1 preparation, leptin (green lines) reduced the EOG signals (control recordings in black solid lines) with partial recovery (black dotted lines). Right: graph summarizes the normalized EOG signals from 14 preparations. 
A
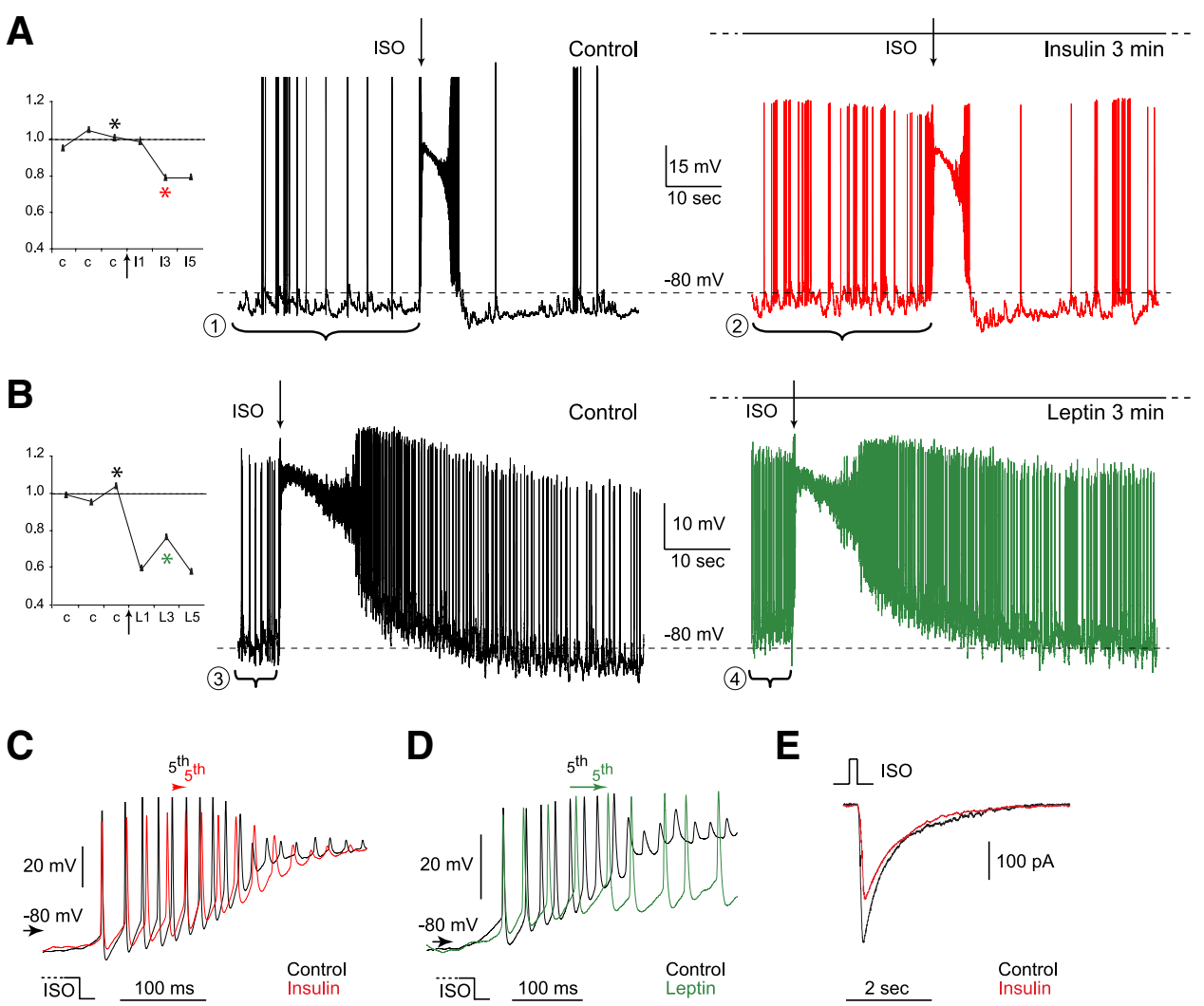

FIG. 6. Insulin and leptin mainly decrease odorant responses of individual OSNs. All recordings were obtained in perforated patch-clamp configuration. ISO stimulations $(250 \mathrm{~ms}, 100 \mu \mathrm{M})$ were interspaced by $2 \mathrm{~min} A$ and $B$ : continuous recordings of 2 single OSNs were obtained under current-clamp mode. As depicted on the protocol graphs (left), 3 ISO stimulations were applied in the control condition (c) and during insulin or leptin perfusion, starting at the arrow. For each response, the firing frequency measured within the initial burst is normalized to the averaged frequency obtained from the 3 controls. Black asterisk marks the control response represented by the black trace on the right. Red and green asterisks mark the responses under insulin (red trace) and leptin (green trace) perfusion, respectively. After $3 \mathrm{~min}$ of insulin perfusion $(A)$, the spontaneous activity measured 1 min before ISO stimulation increased from $1.0 \mathrm{~Hz}$ (bracket 1 ) to $4.9 \mathrm{~Hz}$ (bracket 2). After $3 \mathrm{~min}$ of leptin perfusion (B), the spontaneous activity increased from $3.5 \mathrm{~Hz}$ (bracket 3 ) to $8.1 \mathrm{~Hz}$ (bracket 4 ). $C$ and $D$ : ISO-induced responses shown in $A$ and $B$ are superimposed and enlarged to show the initial bursts in $C$ and $D$, respectively. Insulin decreased the mean instantaneous frequency from 60.4 to $47.7 \mathrm{~Hz}(C)$ and leptin from 41.6 to $26.3 \mathrm{~Hz}(D)$. The arrows indicate the time shift of the 5th action potentials under control and peptide perfusion. $E$ : under voltage-clamp, insulin perfusion decreased the transduction currents evoked by ISO $(250 \mathrm{~ms}, 100 \mu \mathrm{M})$ from $393 \mathrm{pA}$ (black trace) to $263 \mathrm{pA}$ (red trace) in a single OSN. The membrane potential was held at $-80 \mathrm{mV}$.

the control) under peptide (insulin or leptin) perfusion for the ten cells with a nonzero baseline firing (Fig. 7C). The three cells with an increased isoamyl acetate-induced firing (orange) tend to show a more profound increase in the spontaneous firing frequency than those displaying a decreased isoamyl acetate-induced firing (blue). Overall, the EOG and single-cell recordings indicate that insulin and leptin mainly reduce odorant-induced responses in OSNs.

\section{I S C U S S I O N}

Using electrophysiological approaches, we have investigated the influence of two anorectic peptides, insulin and leptin, on the functional properties of OSNs in the absence or presence of odorants. While insulin and leptin dramatically enhance the excitability of OSNs assessed by spontaneous or electrically evoked events, they significantly reduced the odorant-induced activity measured by either EOG or single-cell recordings. The results suggest that an elevated blood level of insulin and leptin after meals may result in a decreased signalto-noise ratio of the odor inputs and thus modulate the smell function to match the satiety status. The potential role of these food intake peptides in stabilizing the epithelio-bulbar connec- tions by upregulating the spontaneous activity of OSNs is also discussed.

\section{OSNs fire spontaneously in a bursting mode}

We analyzed the spontaneous activity of OSNs in either cell-attached or perforated patch-clamp configuration. The cell-attached recording is less invasive and thus keeps the neurons closer to their physiological conditions, whereas the perforated patch-clamp enables direct recording and manipulation of the membrane potential. The spontaneous activity of OSNs is clearly bursting even though the mean firing frequency is lower in perforated patch-clamp recordings (Fig. 1). This is due to a small hyperpolarizing current injected into the neurons to avoid "overfiring," so that the cells can be recorded long enough to study the peptide effects. The spontaneous firing frequency of rat OSNs has also been obtained with an in vivo approach using the extracellular, single-unit recording (Duchamp-Viret et al. 1999, 2005). In this latter report, $40 \%$ of in vivo OSNs fire at $>1.7 \mathrm{~Hz}$ compared with $77 \%$ of in situ cells in the intact epithelium recorded in cell-attached configuration in the current study. This is probably due to the differences between the two preparations and 


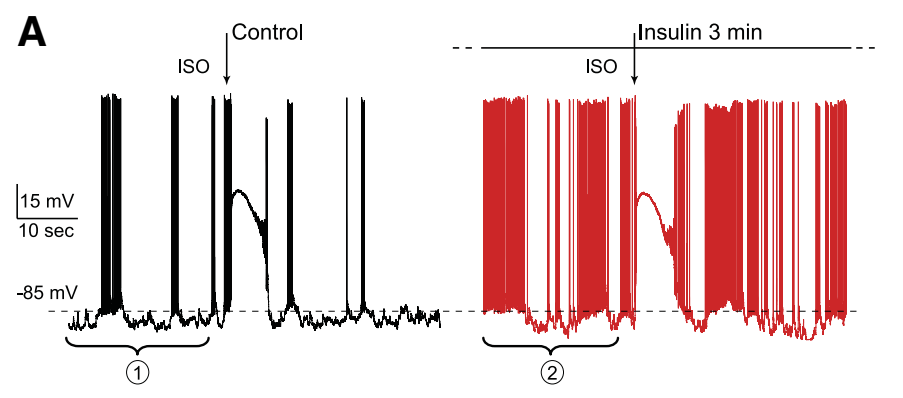

B

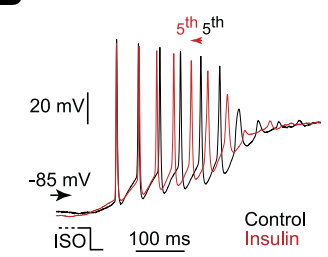

C

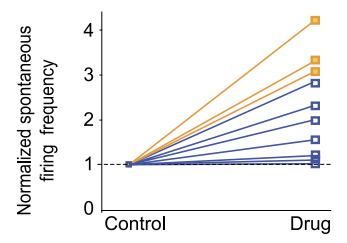

FIG. 7. Insulin and leptin increase the firing frequency of odorant-induced responses in a small number of OSNs. $A$ : continuous patch-clamp recording of a single OSN was obtained under current-clamp mode. Three ISO stimulations ( $250 \mathrm{~ms}, 100 \mu \mathrm{M}$, arrows) interspaced by 2 min were applied in the control condition (black trace) and during insulin perfusion ( $A$, red trace). One response is illustrated for each condition. After $3 \mathrm{~min}$ of insulin perfusion $(A)$, the spontaneous activity increased from $46.3 \mathrm{~Hz}$ (bracket 1) to $52.2 \mathrm{~Hz}$ (bracket 2). B: ISO-induced responses shown in $A$ are superimposed and enlarged to show the initial bursts. The arrow indicates the time shift of the 5 th action potentials under control and peptide perfusion. $C$ : the normalized firing frequencies (to the control) are plotted for the 10 neurons with a nonzero baseline firing. The 3 cells that displayed an increase in ISO-induced firing (orange) tend to show a more profound increase in the spontaneous firing frequency than the cells that displayed a decrease in ISO-induced firing (blue).

recording methods. The in vivo and in vitro OSNs are subject to rhythmic breathing and bath perfusion, respectively, which may affect the spontaneous discharge of some OSNs via their mechanosensitivity (Grosmaitre et al. 2007).

\section{OSNs display various response patterns to odorant stimulation}

We observed a large proportion of OSNs (54.7\%) showing an excitatory response to isoamyl acetate, consistent with a previous in vivo study (60\%) (Duchamp-Viret et al. 2000). However, we detected more inhibitory responses (20 vs. $5 \%$ ) in perforated patch-clamp recordings, in which inhibition is readily identified by membrane hyperpolarization. In contrast, in in vivo single-unit recordings, inhibition appears as a decrease in the firing frequency, which may be too subtle to be noticed or simply hidden under a low-frequency spontaneous firing.

When the rat OSNs were stimulated by brief puffs of isoamyl acetate, we frequently encountered two response patterns: the simple nondecrementing burst and the "burst/silence/ rebound (b/s/r) pattern" (Fig. 4). During the initial burst of the $\mathrm{b} / \mathrm{s} / \mathrm{r}$ pattern, the amplitude of action potentials decreases. This is likely attributed to a current shunt (a decreased membrane resistance) caused by the transduction current and progressive inactivation of voltage-gated $\mathrm{Na}^{+}$channels caused by depolarization (Lynch and Barry 1991; Narusuye et al. 2003; Trotier and MacLeod 1983). The same mechanisms may also lead to the silence period. Initiation of the rebound spikes relies on decrease of this shunt and on re-activation of voltage-gated $\mathrm{Na}^{+}$currents when the membrane potential repolarizes.

Similar response patterns have been reported in mammalian and amphibian OSNs (Duchamp-Viret et al. 2000; Reisert and Matthews 2001; Rospars et al. 2003). In single-unit recordings from in vivo rat OSNs (Duchamp-Viret et al. 2000), a low concentration odorant stimulation evokes a simple nondecrementing burst, and a medium concentration elicits a " $\mathrm{b} / \mathrm{s} / \mathrm{r}$ " pattern. For a high concentration, the duration of the initial burst decreases and its firing frequency increases, while the silence becomes longer. The concentration-dependent changes do not rely on the odorant quality but depend on the odorant sensitivity of the OSNs. In our in vitro recordings, the same isoamyl acetate stimulation elicited patterns corresponding to low-, medium-, and high-strength responses, indicating a broad sensitivity among OSNs. Taken together, the in vitro OSNs in the intact epithelium closely resemble those under in vivo conditions in their odorant-induced activity.

\section{Insulin and leptin may play several roles in the olfactory system}

The most striking finding in our study is that bath perfusion of insulin or leptin significantly increases the spontaneous firing but reduces odorant-induced activity in OSNs. The underlying mechanisms are likely attributed to two factors: the ionic channels responsible for the spontaneous activity are different from those involved in odorant signal transduction (Kleene 2008; Narusuye et al. 2003) and insulin and leptin interact with different channels (Fadool et al. 2004; Shanley et al. 2002; Spanswick et al. 1997, 2000) and signaling pathways (Bjorbaek and Kahn 2004; Capeau 2005). It is also possible that these two hormones act on the same targets via different signaling pathways as reported in the hypothalamus (Plum et al. 2005). Based on our findings, we propose that insulin and leptin may modulate the smell function at the peripheral level by exerting several actions.

First, insulin and leptin may help stabilizing the epitheliobulbar connections by enhancing the spontaneous activity of OSNs, which undergo continuous cell death and neurogenesis. In the competitive environment of the olfactory epithelium, less-active OSNs have a disadvantage in maintaining their synaptic connections in the olfactory bulb and likely disappear (Yu et al. 2004; Zou et al. 2004). A recent study reveals that genetic deletion of the shaker Kv1.3 channel in the OSNs disturbs the refinement of the primary olfactory projections (Biju et al. 2008; Fadool et al. 2004). More interestingly, insulin inhibits this potassium channel (Fadool et al. 2000), which might lead to the increased firing frequency we observed in the OSNs. Although it requires further investigation to identify the molecular targets for insulin and leptin in the OSNs, the strong effects of these two peptides on the spontaneous activity support a role of these blood-circulating hormones in the olfactory epithelium in the absence of odorant stimulation.

Second, insulin and leptin may reduce the signal-to-noise ratio of the odor inputs to match the smell function with the satiety status. While these two peptides increase the spontaneous activity of OSNs (Fig. 2), they mainly reduce the odorantinduced activity in the olfactory epithelium (Figs. 5 and 6). We first explored the peptide effects using EOG recordings, which summate the receptor potentials from a population of OSNs (Getchell 1974). Consistent with the results from a recent study 
examining the role of insulin in adult rats (Lacroix et al. 2008), here we report similar inhibition induced by insulin (as well as by leptin) in either young or adult rats.

The physiological concentrations of insulin and leptin in the olfactory mucosa have not been experimentally measured. The peptide dose we used is within the physiological range of insulinemia and leptinemia (blood levels of insulin and leptin) and mimics an elevation after a meal for adult rats. Compared with adults, young rats have different insulinemia and leptinemia (Aalinkeel et al. 1999; Bouret and Simerly 2007; Bruder et al. 2004; Li et al. 2004; Mistry et al. 1999; Smith and Waddell 2003) and display different secretion rhythms (Bouret and Simerly 2007; Nagatani et al. 2000). Nevertheless, the similar effects we observed on the EOG signals at both ages indicate that insulin or leptin has comparable functional effects on odorant-induced responses in young and adult tissues.

Although the olfactory epithelium has tight junctions, peptides like insulin and leptin have been shown to enter the circulating systems and the CNS after intranasal instillation (el Khafagy et al. 2007; Foster-Schubert and Cummings 2006). This is likely due to the mucociliary clearance of the peptides and the vascularization of lamina propria in which the capillaries have a porous endothelial basement membrane. Therefore in the EOG recordings, these two peptides should reach their receptors on the OSNs and cause the observed effects. In each experiment, by performing controls using Ringer solution and observing at least a partial recovery after peptide washout, we ruled out nonspecific effects caused by possible disturbance of the recording configurations during drug application. However, these experiments do not completely rule out a nonspecific effect of these peptides unrelated to food intake. Future studies using some circulant orexigenic peptides to show opposite effects on the activity of OSNs would help to tease out the consequences of these peptides.

We then used patch-clamp recordings to analyze the peptide effects on odorant-induced responses of individual OSNs. Both peptides mainly reduce the burst firing and the transduction currents (Fig. 6). Because of the strong stimulatory effects of these two peptides on the spontaneous firing of OSNs, their effects on odorant-induced firing could be concealed (Fig. 7). Therefore the peptide effects are better assessed in changes in the transduction currents or EOG signals, which all show a reduction under peptide application. What would be the consequence of high insulinemia and leptinemia on the olfactory coding in the postprandial context? At the epithelium level, the signal-to-noise ratio of the sensory input transmitted to the olfactory bulb will be reduced. The weaker odorant response will tend to be concealed in the reinforced spontaneous activity.

While our study focuses on the effects of food intake peptides on the olfactory epithelium, they influence the smell function by targeting the olfactory system centrally as well. The olfactory bulb is a target for insulin, leptin, and orexin (Fadool et al. 2004; Getchell et al. 2006; Julliard et al. 2007; Palouzier-Paulignan et al. 2006; Shioda et al. 1998), and the anterior piriform cortex acts as a critical sensor of amino-acids deficiency (Gietzen et al. 2007). Overall, the olfactory system plays an essential role in modulating eating behaviors to match the metabolic status. Conversely, the peptide hormones, which regulate food intake, modulate the sense of smell to match the satiety status.

\section{G R A N T S}

This work was supported by the Agence Nationale de la Recherche (ANR), the French national research agency in the Programme National de Recherche en Alimentation et Nutrition Humaine (project ANR-05-PNRA1.E7 AROMALIM), and the National Institute on Deafness and Other Communications Disorders.

\section{REFEREN CES}

Aalinkeel R, Srinivasan M, Kalhan SC, Laychock SG, Patel MS. A dietary intervention (high carbohydrate) during the neonatal period causes islet dysfunction in rats. Am J Physiol Endocrin Metab 277: E1061-1069, 1999.

Aimé P, Duchamp-Viret P, Chaput MA, Savigner A, Mahfouz M, Julliard AK. Fasting increases and satiation decreases olfactory detection for a neutral odor in rats. Behav Brain Res 179: 258-264, 2007.

Arora S, Anubhuti. Role of neuropeptides in appetite regulation and obesity-a review. Neuropeptides 40: 375-401, 2006.

Baly C, Aioun J, Badonnel K, Lacroix MC, Durieux D, Schlegel C, Salesse R, Caillol M. Leptin and its receptors are present in the rat olfactory mucosa and modulated by the nutritional status. Brain Res 1129: 130-141, 2007.

Biju KC, Marks DR, Mast TG, Fadool DA. Deletion of voltage-gated channel affects glomerular refinement and odorant receptor expression in the mouse olfactory system. J Comp Neurol 506: 161-179, 2008.

Bjorbaek C, Kahn BB. Leptin signaling in the central nervous system and the periphery. Recent Prog Hormone Res 59: 305-331, 2004.

Bouret SG, Simerly RB. Development of leptin-sensitive circuits. J Neuroendocrinol 19: 575-582, 2007.

Bruder ED, Lee PC, Raff H. Metabolic consequences of hypoxia from birth and dexamethasone treatment in the neonatal rat: comprehensive hepatic lipid and fatty acid profiling. Endocrinology 145: 5364-5372, 2004.

Capeau J. Insulin signaling: mechanisms altered in insulin resistance. Med Sci 21: 34-39, 2005.

Chaput M, Holley A. Olfactory bulb responsiveness to food odour during stomach distension in the rat. Chem Senses 2: 189-201, 1976.

Duchamp-Viret P, Chaput MA, Duchamp A. Odor response properties of rat olfactory receptor neurons. Science 284: 2171-2174, 1999.

Duchamp-Viret P, Duchamp A, Chaput MA. Peripheral odor coding in the rat and frog: quality and intensity specification. J Neurosci 20: 2383-2390, 2000.

Duchamp-Viret P, Kostal L, Chaput M, Lansky P, Rospars JP. Patterns of spontaneous activity in single rat olfactory receptor neurons are different in normally breathing and tracheotomized animals. J Neurobiol 65: 97-114, 2005.

el Khafagy S, Morishita M, Onuki Y, Takayama K. Current challenges in non-invasive insulin delivery systems: a comparative review. Adv Drug Delivery Rev59: 1521-1546, 2007.

Fadool DA, Tucker K, Perkins R, Fasciani G, Thompson RN, Parsons AD, Overton JM, Koni PA, Flavell RA, Kaczmarek LK. Kv1.3 channel gene-targeted deletion produces "Super-Smeller Mice" with altered glomeruli, interacting scaffolding proteins, and biophysics. Neuron 41: 389-404, 2004.

Fadool DA, Tucker K, Phillips JJ, Simmen JA. Brain insulin receptor causes activity-dependent current suppression in the olfactory bulb through multiple phosphorylation of Kv1.3. J Neurophysiol 83: 2332-2348, 2000.

Foster-Schubert KE, Cummings DE. Emerging therapeutic strategies for obesity. Endocrin Rev 27: 779-793, 2006.

Getchell TV. Electrogenic sources of slow voltage transients recorded from frog olfactory epithelium. J Neurophysiol 37: 1115-1130, 1974.

Getchell TV, Kwong K, Saunders CP, Stromberg AJ, Getchell ML. Leptin regulates olfactory-mediated behavior in ob/ob mice. Physiol Behav 87: 848-856, 2006.

Gietzen DW, Hao S, Anthony TG. Mechanisms of food intake repression in indispensable amino acid deficiency. Annu Rev Nutr 27: 63-78, 2007.

Gorojankina T, Grebert D, Salesse R, Tanfin Z, Caillol M. Study of orexins signal transduction pathways in rat olfactory mucosa and in olfactory sensory neurons-derived cell line Odora: multiple orexin signalling pathways. Regulatory Peptides 141: 73-85, 2007.

Grosmaitre X, Santarelli LC, Tan J, Luo M, Ma M. Dual functions of mammalian olfactory sensory neurons as odor detectors and mechanical sensors. Nat Neurosci 10: 348-354, 2007.

Hardy AB, Aioun J, Baly C, Julliard KA, Caillol M, Salesse R, DuchampViret P. Orexin A modulates mitral cell activity in the rat olfactory bulb: patch-clamp study on slices and immunocytochemical localization of orexin receptors. Endocrinology 146: 4042-4053, 2005. 
Julliard AK, Chaput MA, Apelbaum A, Aime P, Mahfouz M, DuchampViret $\mathbf{P}$. Changes in rat olfactory detection performance induced by orexin and leptin mimicking fasting and satiation. Behav Brain Res 183: 123-129, 2007.

Kleene SJ. The electrochemical basis of odor transduction in vertebrate olfactory cilia. Chem Senses 33: 839-859, 2008.

Lacroix MC, Badonnel K, Meunier N, Tan F, Poupon CS, Durieux D, Monnerie R, Baly C, Congar P, Salesse R, Caillol M. Expression of insulin system in the olfactory epithelium: first approaches to its role and regulation. J Neuroendocrinol 20: 1176-1190, 2008.

Le Magnen J. Role de l'odeur ajoutée au régime dans la régultaion quantitative à court terme de la prise alimentaire chez le Rat blanc. C R Soc Biol 150: 136-139, 1956.

Le Magnen J. My scientific life: 40 years at the College de France. Neurosci Biobehav Rev 25: 375-394, 2001.

Li L, Yi Z, Seno M, Kojima I. Activin A and betacellulin: effect on regeneration of pancreatic beta-cells in neonatal streptozotocin-treated rats. Diabetes 53: 608-615, 2004.

Lynch JW, Barry PH. Properties of transient $\mathrm{K}^{+}$currents and underlying single $\mathrm{K}^{+}$channels in rat olfactory receptor neurons. J Gen Physiol 97: 1043-1072, 1991.

Ma M, Grosmaitre X, Iwema CL, Baker H, Greer CA, Shepherd GM. Olfactory signal transduction in the mouse septal organ. J Neurosci 23: 317-324, 2003.

Mistry AM, Swick A, Romsos DR. Leptin alters metabolic rates before acquisition of its anorectic effect in developing neonatal mice. Am J Physiol Regultory Integrative Comp Physiol 277: R742-747, 1999.

Nagatani S, Guthikonda P, Foster DL. Appearance of a nocturnal peak of leptin secretion in the pubertal rat. Hormones Behav 37: 345-352, 2000.

Narusuye K, Kawai F, Miyachi E. Spike encoding of olfactory receptor cells. Neurosci Res 46: 407-413, 2003.

Palouzier-Paulignan B, Savigner A, Duchamp-Viret P. Insulin reduces several types of potassium conductances in mitral cell. Chem Senses 31: E1-E104, P124, 2006.

Plum L, Schubert M, Bruning JC. The role of insulin receptor signaling in the brain. Trends Endocrinol Metab 16: 59-65, 2005.

Rajendra S, Lynch JW, Barry PH. An analysis of $\mathrm{Na}^{+}$currents in rat olfactory receptor neurons. Pfluegers 420: 342-346, 1992.

Reisert J, Matthews HR. Responses to prolonged odour stimulation in frog olfactory receptor cells. J Physiol 534: 179-191, 2001.
Rospars JP, Lansky P, Duchamp A, Duchamp-Viret P. Relation between stimulus and response in frog olfactory receptor neurons in vivo. Eur J Neurosci 18: 1135-1154, 2003.

Schwartz MW, Woods SC, Porte D, Jr, Seeley RJ, Baskin DG. Central nervous system control of food intake. Nature 404: 661-671, 2000.

Seguy M, Perret M. Changes in olfactory inputs modify the energy balance response to short days in male gray mouse lemurs. Physiol Behav 84: 23-31, 2005.

Shanley LJ, O’Malley D, Irving AJ, Ashford ML, Harvey J. Leptin inhibits epileptiform-like activity in rat hippocampal neurones via PI 3-kinasedriven activation of BK channels. J Physiol 545: 933-944, 2002.

Shioda S, Funahashi H, Nakajo S, Yada T, Maruta O, Nakai Y. Immunohistochemical localization of leptin receptor in the rat brain. Neurosci Lett 243: 41-44, 1998.

Smith JT, Waddell BJ. Developmental changes in plasma leptin and hypothalamic leptin receptor expression in the rat: peripubertal changes and the emergence of sex differences. J Endocrinol 176: 313-319, 2003.

Spanswick D, Smith MA, Groppi VE, Logan SD, Ashford ML. Leptin inhibits hypothalamic neurons by activation of ATP-sensitive potassium channels. Nature 390: 521-525, 1997.

Spanswick D, Smith MA, Mirshamsi S, Routh VH, Ashford ML. Insulin activates ATP-sensitive $\mathrm{K}^{+}$channels in hypothalamic neurons of lean, but not obese rats. Nat Neurosci 3: 757-758, 2000.

Stanley S, Wynne K, McGowan B, Bloom S. Hormonal regulation of food intake. Physiol Rev 85: 1131-1158, 2005.

Trombley PQ, Westbrook GL. Voltage-gated currents in identified rat olfactory receptor neurons. J Neurosci 11: 435-444, 1991.

Trotier D, MacLeod P. Intracellular recordings from salamander olfactory receptor cells. Brain Res 268: 225-237, 1983.

Vigouroux M, Viret P, Duchamp A. A wide concentration range olfactometer for delivery of short reproducible odor pulses. J Neurosci Methods 24: 57-63, 1988.

Yu CR, Power J, Barnea G, O'Donnell S, Brown HE, Osborne J, Axel R, Gogos JA. Spontaneous neural activity is required for the establishment and maintenance of the olfactory sensory map. Neuron 42: 553-566, 2004.

Zou DJ, Feinstein P, Rivers AL, Mathews GA, Kim A, Greer CA, Mombaerts P, Firestein S. Postnatal refinement of peripheral olfactory projections. Science 304: 1976-1979, 2004. 